\title{
The space of media usage in Finland, 2007 and 2018
}

\author{
The impact of online activities on its structure \\ and its association with sociopolitical divisions
}

\author{
Semi Purhonen, ${ }^{I}$ Adrian Leguina, ${ }^{\text {II }}$ \& Riie Heikkilä ${ }^{\mathrm{I}}$ \\ ${ }^{\mathrm{I}}$ Faculty of Social Sciences, Tampere University, Finland \\ II School of Social Sciences and Humanities, Loughborough University, UK
}

\begin{abstract}
In Nordic countries and beyond, there exists a lack of longitudinal, population-level research focused on sociopolitical polarisation and the proliferation of new online activities in the context of changing media usage. In this article, we examine media usage in Finland in 2007 and 2018. We use two nationally representative surveys $(N=1,388$ in 2007 and $N=1,425$ in 2018) to make comparisons over time and include a wide set of media usage indicators. Applying multiple correspondence analysis, we assess the impact of the proliferation of online activities on the structure of the space of media usage and examine whether the association between media usage and sociopolitical divisions has become more sharply pronounced. The results suggest stability of the structure of media use rather than dramatic change. We discuss these results by reflecting on the relatively strong persistence of "traditional" models of stratification in digital cultural consumption and media practices.
\end{abstract}

Keywords: media usage, online activities, stratification, change, multiple correspondence analysis

\section{Introduction}

The social changes faced by the Western world during the first two decades of the twenty-first century include rising inequalities, nationalist-populist movements and identity politics, and the simultaneous rise of social media and digitalisation of culture. This signifies a major transformation in the media landscape. Yet, research focusing on both sociopolitical polarisation and the proliferation of new online activities in the context of changing media usage is generally scarce (see, however, Bergström et al., 2019; Koiranen et al., 2020; Strömbäck et al., 2013). While there is a strong consensus that the changes in the media landscape and usage have been profound, opinions are divided regarding the role of new online activities, with respect to the ways in which media consumption is socially stratified.

Purhonen, S., Leguina, A., \& Heikkilä, R. (2021). The space of media usage in Finland, 2007 and 2018: The impact of online activities on its structure and its association with sociopolitical divisions. Nordicom Review, 42(S3), 111-128. https://doi.org/10.2478/nor-2021-0029 
On the one hand, there is a significant body of literature emphasising that "traditional" patterns of stratification still hold with regard to digital media consumption. Major parts of the so-called digital divide or digital inequality research show that inequalities in terms of unequal access, skills, and accumulated benefits relating to the usage of digital media can be attributed to well-established divisions according to age, education, and class (e.g., DiMaggio et al., 2004; Norris, 2001; Scheerder et al., 2017; Zillien \& Hargittai, 2009). Thus, sociodemographic polarisation in digital media consumption is mostly found to deepen "old" divisions and hierarchies (in that highly educated professionals and young groups are most engaged with digital media) and does not necessarily create new ones (e.g., Heikkilä et al., 2020; Lindell \& Hovden, 2018; Mihelj et al., 2019; Yuen et al., 2018; Ørmen, 2019).

On the other hand, some scholars argue for a more profound transformation; namely, that the Internet, digital media, and social media platforms represent a democratising force capable of levelling the inequalities typical of traditional media usage (see Xenos et al., 2014), or stand for entirely novel ways of stratification, altering the whole logic according to which cultural and media consumption marks class (see Beer, 2013; Webster, 2019, 2020). Accordingly, first, digital environments and means of circulation produce a new "high-choice" media environment representing unprecedented breeding grounds for adventurous and "omnivorous" tastes (Beer, 2013; Prior, 2007; Wright, 2015). Second, online platforms and algorithms (e.g., via their recommendation systems) have become the infrastructures that increasingly shape "encounters with culture", in addition to the traditional taste communities based on individuals' sociodemographic position and offline interactions and networks (Beer, 2013; Webster, 2019, 2020). Third, "amateur" or peer-produced reviewing in social media and other online platforms challenges the cultural authority of traditional criticism (Kristensen et al., 2018; Verboord, 2014). Fourth, it has been argued that social media has entailed unprecedented audience fragmentation furthering political polarisation, although the evidence for this is mixed (e.g., Dubois \& Blank, 2018). According to these perspectives, online media ultimately signify "a potential shift in the ontology of taste formation" (Beer, 2013: 97).

Finally, a somewhat moderate stance in the discussion is represented by the arguments for "emerging forms of cultural capital" (Friedman et al., 2015; Prieur \& Savage, 2013), of which some would indicate the capacity to use digital technologies (see also Savage 2015; Savage et al., 2013). This scenario can be understood as dubbing the relatively well-established insights of the digital divide literature (e.g., Zillien \& Hargittai, 2009) into the vocabulary of cultural capital (Bourdieu, 1984) when assessing what counts as beneficial cultural resources in present-day societies. Thus, while the view of emerging forms of cultural capital emphasises that digital media consumption constitutes a new source of cultural and "technological" inequality, it is less clear whether it implies something genuinely new besides the accentuation of old (class-based and age-related) hierarchies.

Taken together, there are varying positions relating to the question of how digitalisation and new online activities have impacted the structure of media usage and its sociopolitical organisation over the last ten to fifteen years. Surely, these divisions in the previous literature might be based not only on conflicting research evidence, but also on divergent writing genres, foci, and methodological approaches across different studies. Nevertheless, it remains a divisive question how the proliferation of online activities has shaped media usage and related social hierarchies. 
Another complex aspect in the literature is that the relationship between politics and media usage, as well as the concept of polarisation, have been understood in various ways. Not only is the relationship between politics and media usage causally reciprocal (Boulianne, 2011); also, the concept of politics itself has various meanings. Important for us are the conceptions of political engagement, particularly the understandings of politics as orientation or interest (Couldry et al., 2010). Political orientation can be seen simultaneously as preconditioning the habitus and dispositions of the individuals (along with socioeconomic and demographic factors) and as being produced by them (along with cultural practices); political orientation is thus a crucial element in lifestyle differentiation, encompassing also media usage (Bourdieu, 1984). Relating to the much-debated link between new media and polarisation (Tucker et al., 2018), we use the concept of polarisation to refer simply to a process in which social and political differentiation of media usage become more pronounced over time (DiMaggio et al., 1996).

A very limited number of studies are capable of investigating potential changes in sociopolitical stratification of media usage empirically through systematic populationlevel datasets. First, examining these questions requires longitudinal settings and including comparable information of all the necessary variables (on media usage, sociodemographic characteristics, and political orientations). As trivial as this might sound, scholars have rarely been able to focus on temporal change concerned with how new forms of digital and social media have impacted sociopolitical stratification of media usage over the last ten to fifteen years. Second, investigating these questions requires a holistic approach involving "overall" media usage against which it is possible to measure the impact of new digital media activities. Thus, media usage must be conceptualised as a comprehensive and potentially multidimensional "media repertoire" (Hasebrink \& Popp, 2006), a "lifestyle" (Bourdieu, 1984), or some other set of "media practices" of an individual (Lindell \& Hovden, 2018).

This article offers a population-level analysis of the change in media usage in Finland from 2007 to 2018 (drawing on representative and comparative data from both years, thus fulfilling the first requirement). It employs a novel methodological approach based on multiple correspondence analysis (MCA), by which we construct a general "space of media usage" in Finland against which the impact of online activities can be observed (thus fulfilling the second requirement). MCA is one of the few methods particularly suitable for this, due to its capacity to inductively analyse and visualise multivariate associations across several categorical media usage indicators and their relationships with sociopolitical divisions. Thus, we aim to assess the impact of the proliferation of online activities on the structure of the space of media usage and find out whether the association between the structure of the space and sociopolitical divisions has become more pronounced. Our study contributes to the emerging literature on the stratification and inequalities of media usage broadly inspired by Bourdieu (e.g., Lindell, 2018; Lindell \& Hovden, 2018; Mihelj et al., 2019) by a unique over-time emphasis on the role of the political along with the social in "stratification".

Besides data availability reasons, the time span of 2007-2018 is particularly suitable for our analysis, as 2007 is precisely when social media usage started to explode in Finland and elsewhere in Europe (e.g., the worldwide launch of iPhone and the start of the growing popularity of Facebook; Purhonen et al., 2014). Thus, regarding media usage, 2007 stands for the last year one can consider representing the pre-social media 
era. Moreover, in terms of politics, 2007 was the last year when the nationalist-populist Finns Party had only small support in the parliamentary elections $(4.05 \%)$, later notably increasing its popularity, even if it has fluctuated dramatically during the four-year electoral terms.

Our analysis, inspired by the few studies that have used MCA for analysing temporal changes (e.g., Coulangeon, 2013; Rosenlund, 2019; Weingartner \& Rössel, 2019), includes three steps. First, we construct the space of media use for 2007 using 19 indicators of media usage, ranging from television watching to newspaper, magazine, and book readership, and Internet usage as active variables, while sociopolitical divisions (projected onto the space as supplementary variables) are measured by basic sociodemographic characteristics as well as party support and political attitudes (conservative versus liberal). Second, we include 2018 respondents' media repertoires and sociodemographic information as supplementary individuals and variables into the space of 2007. Third, we construct the space of media usage for 2018 again, this time using not only the same indicators but also 16 additional indicators of social media usage and other online activities not available for the 2007 data. This last step allows an inspection of the degree to which the new media activities have shaped the structure of the media-use space and whether it matters regarding how the structure is associated with sociopolitical divisions.

The empirical context of this study is Finland, sometimes labelled one of the "media welfare states" (Syvertsen et al., 2014). Finland, along with other Nordic countries, has comparatively small educational and income inequalities. It also has a relatively de-commodified public sector, with state-driven cultural policy and a democratic corporatist media system model (Hallin \& Mancini, 2004; Purhonen et al., 2019). Perhaps unsurprisingly, many Finnish sociologists, especially in the 1980s and 1990s, saw Finland culturally as a relatively homogenous society. However, as in the case of other Nordic countries (see Prieur \& Savage, 2013), recent research has shown that lifestyle differentiation and cultural hierarchies in Finland are basically similar as elsewhere in the Global North (e.g., Purhonen, 2020; Purhonen et al., 2014).

In terms of political landscape, Finland is a parliamentary democracy with a centreleft tendency, usually ruled by coalition governments. There are three major traditional parties: the Social Democratic Party, the Centre Party, and the National Coalition Party. However, the Green League and, especially, the Finns Party have increased their popularity in recent decades, the latter being a Finnish version of internationally risen nationalist-populist parties fuelled by anti-EU and anti-immigration sentiments. Regarding political attitudes and values, the megatrend has been towards more liberal stances. Overall, the "new" politics (or identity politics) has increased its prominence at the cost of "old" politics (or politics of redistribution) (Harrits et al., 2010), also in Finland.

The article is organised as follows. In the next section, we describe our data, variables, and analytical strategy. The results section proceeds in three steps, mentioned above. Finally, we summarise our results and discuss whether the new pattern of digital media consumption has been important in restructuring the Finnish space of media usage between 2007 and 2018 . 


\section{Data and methods}

The dataset derives from two nationally representative postal surveys collected by Statistics Finland in $2007(N=1,388$; response rate 46.3\%; sample of 3,000) and $2018(N=$ $1,425$; response rate $40.8 \%$; sample of 3,500$)$. Both cover the $18-74$-year-old mainland Finnish population. These cross-sectional surveys were designed to allow for comparison and therefore have a high degree of comparability in terms of topics covered and exact formulations and items mentioned in the questions. Both datasets include a weight variable provided by Statistics Finland to correct the non-response bias with regard to respondents' age, gender, education, and residential area. In this article, we used the unweighted datasets, as there was little difference in the results between weighted and unweighted samples.

The space of media usage is built on a wide range of variables covering five different media forms: television, newspapers, magazines, books, and Internet or online media. These indicators of media usage (19 in total, divided into 41 modalities) are the active variables in the analysis. The categories of the selected variables (e.g., reads or does not read something), which were identical for 2007 and 2018, are marked on the figures (i.e., spaces) with their exact location and defined as follows:

- Television (3 variables, 7 modalities): hours a day (1 or less; 2-3; 4 or more); watches regularly YLE TV1 (yes/no); watches regularly SubTV (yes/no).

- Newspapers (3 variables, 6 modalities): reads regularly Helsingin Sanomat (yes/ no); reads regularly tabloids (yes/no); reads any newspaper regularly (yes/no).

- Magazines (3 variables, 6 modalities): reads sometimes Suomen Kuvalehti (yes/ no); reads sometimes 7 päivää (yes/no); reads any magazine sometimes (yes/no).

- Books (3 variables, 7 modalities): number of books read last year (none; 1-10; 11 or more); has read Dostoyevsky's Crime and Punishment (yes/no); has read Dan Brown's The Da Vinci Code (yes/no).

- Internet (7 variables, 15 modalities): frequency of Internet usage (never or rarely; weekly; once a day or more); uses Internet for following news or sports (yes/ no); uses Internet for reading newspapers or magazines (yes/no); uses Internet for discussing or "chatting” (yes/no); uses Internet for gaming or gambling (yes/ no); uses Internet for listening to or downloading music (yes/no); uses Internet for watching or downloading films or videos (yes/no).

We also include additional online activities for 2018 (16 variables in total, divided into 33 modalities):

- Streaming service usage (4 variables, 8 modalities): watches regularly Katsomo (yes/no); watches regularly Ruutu (yes/no); watches regularly other paid service (yes/no); watches regularly YLE Areena (yes/no).

- Internet and social media (12 variables, 25 modalities): number of devices to connect to Internet $(0 ; 1-2 ; 3$ or more); uses online message application (yes/no); uses regularly YouTube (yes/no); uses regularly Facebook (yes/no); uses regularly Twitter (yes/no); uses regularly Instagram (yes/no); uses regularly TripAdvisor (yes/no); uses regularly Suomi 24 discussion forum (yes/no); uses regularly tabloids' discussion forums (yes/no); uses regularly MV magazine's website (yes/no); uses regularly some hobby-related website or online community (yes/no); uses regularly some political website or online community (yes/no). 
To determine the sociodemographic divisions, we included in our analysis the following factors (as supplementary variables), repeatedly found important in studies on the social stratification of cultural practices (see, e.g., Prieur \& Savage, 2013; Purhonen et al., 2014): gender (male/female); education (no/basic; vocational; college; university degree); income (low; middle; high); age (18-24; 25-34; 35-44; 45-54; 55-64; 65-74); and residential area (urban/rural). For political divisions (see DellaPosta et al., 2015; Jarness et al., 2019), we included as supplementary variables party support (9 categories in 2007 and 10 in 2018) - Centre Party; National Coalition Party; Christian Democrats; Finns Party; Swedish People's Party of Finland; Blue Reform (only in 2018); Social Democratic Party; Left Alliance; Green League; would not vote) - and conservative versus liberal attitudes (scale $0-20$, recoded in four quartiles: 7 or less; $7-10 ; 11-13 ; 13$ or more). All the necessary information from the perspective of MCA regarding all variables (categories, category labels, distributions, coordinates, test values and, in case of active variables, their contributions to the main axes) are reported in the Supplementary Material file (see Tables A1 and A2).

Our methodological approach, which is part of the family of geometric data analysis methods (Le Roux \& Rouanet, 2004), seeks to describe the most important information on geometric visual representations (biplots), and specific to our research, it compares the spaces of media usage in 2007 and 2018 by taking a two-step "historic profiles" approach (Müller-Schneider, 1994; see also Coulangeon, 2013; Rosenlund, 2019). The first step involves the application of MCA to 2007 cross-sectional data. MCA is a dimension reduction technique to analyse categorical data. The objective of the analysis is to detect patterns of association across media usage by decomposing the main sources of variation into fewer dimensions (axes) and providing summary values which can be plotted as clouds to visualise interrelations among individuals and categorical variables, alongside sociodemographic characteristics as supplementary variables (Le Roux \& Rouanet, 2004).

The first wave of the survey, according to this approach, produces what we consider the reference situation for our study of social change. The second step involves the inclusion of 2018 respondents' media repertoires and demographic information as supplementary individuals and variables into the space representing the situation in 2007. In other words, 2018 respondents are projected onto the space built using 2007 respondents' answers by using the same set of active and supplementary variables. The resulting joint representation allows us to visualise and statistically assess changes in media usage in terms of cloud location and dispersion, with 2007 individuals representing the initial, and 2018 individuals the end, situation. Finally, we present a "full" picture of current media usage by applying MCA to 2018 data, including additional active variables on online activities and social media usage that were not part of the original study in 2007 . This complements our historic profiles approach by offering richer insights into the changes on people's media repertoires. The interpretation of results consists of identification of patterns of media engagement and sociopolitical information, across each axis individually and regions, in the space by visual inspection of categories' coordinates (the closer these categories are, the stronger their association is), quantification of contributions (amount of variability due to a specific category or combination of categories), as well as test values (statistical significance of the deviation of each category from the origin on each axis in the space). 


\section{Results}

Step 1: Space of media usage in 2007

We start by constructing the space of media usage in Finland in 2007 by including our 19 variables (divided into 41 modalities) in the analysis. Table 1 shows the first five dimensions produced by MCA and how strongly they structure the data regarding the above-mentioned set of modalities and their interconnections.

Table 1 Variances of axes, explained variances, and modified rates in constructing the space of media usage in Finland, 2007

\begin{tabular}{lccc}
\hline Axis & Variance & \% of explained variance & $\begin{array}{c}\text { Benzécri's modified rates } \\
\text { (\%) }\end{array}$ \\
\hline 1 & .204 & 17.6 & 77.1 \\
2 & .127 & 11.0 & 19.2 \\
3 & .080 & 6.9 & 3.0 \\
4 & .062 & 5.3 & 0.4 \\
5 & .058 & 5.0 & 0.2 \\
\hline
\end{tabular}

Usually, the number of axes to be interpreted in the space is limited to two, or at most four (Greenacre, 2007). The final choice is made by examining the eigenvalues of the axes separated by the MCA and the amount of modified inertia explained by the axes (Le Roux \& Rouanet, 2010). Here, the eigenvalues of the third and fourth axes (and especially the modified rates) are considerably smaller than for the two first axes. The first axis explains about three-quarters of the modified inertia and the second axis almost 20 per cent. Thus, when interpreting the space for 2007 , we focus on the two first dimensions only, of which the overwhelmingly most powerful axis 1 will be visualised as the horizontal $\mathrm{x}$-axis and the next strongest axis 2 as the vertical $\mathrm{y}$-axis.

The space of media usage in Finland for 2007 is presented in Figure 1, and detailed results are reported in the Supplementary Material file (see Tables A3 and A4). In the centre of the space, there is the neutral and undifferentiating (and generally very popular) media use in terms of the main axes, while the most differentiating (and typically less popular) media use can be found on the margins of the space. In principle, it is equally interesting to know which modalities are located in the neutral centre than in the most distinctive extremities of the map.

The horizontal axis 1 seems to clearly separate Internet usage versus non-usage, with the different purposes of Internet use located on the right (watching and downloading movies being located on the extreme right) along with using the Internet many times a day. Conversely, on the left side of the space, there are the different "non-usages" of the Internet, never using the Internet located on the most extreme left. Thus, already in 2007, the Finnish space of media usage was first and foremost divided by varying levels of Internet usage. The vertical axis 2, in turn, clearly separates the variables of traditional media usage versus non-usage - with a noticeable legitimacy-related twist. In other words, the most legitimate (or highbrow-oriented) forms of traditional media are located on the top of the space (reading Dostoyevsky, reading the leading national newspaper Helsingin Sanomat, and reading extensively in general), while a few particu- 
larly popular (or illegitimate) media practices, such as watching significant amounts of television and reading the gossip magazine 7 päivää, are located in the bottom half of the space amongst the other, mostly "passive", items describing non-usage. When it comes to the modalities of Internet usage that mostly differentiate according to the horizontal axis, they (like most of the different purposes of using the Internet) are mostly located in the bottom half of the space.

Figure 1 The space of media usage in Finland in 2007 (41 modalities), axes 1 and 2

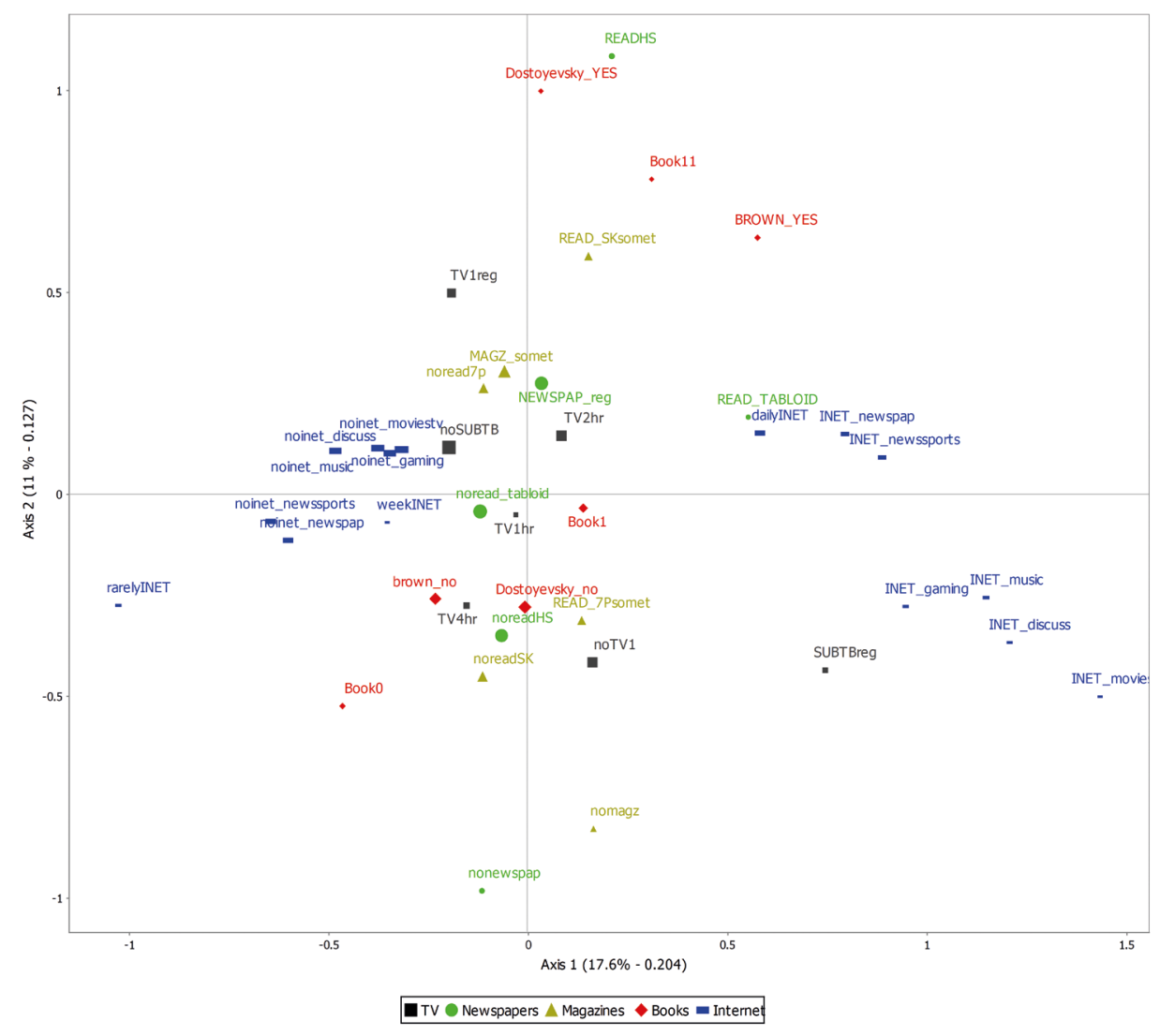

Comments: Shape size is proportional to their frequency in the sample.

Perhaps the easiest way to interpret the space is to divide it into four squares or "corners" defined by the horizontal (Internet usage-related) and vertical (traditional media usage-related) dimensions (Hjellbrekke, 2019). Thus, the area in the top-right quarter of the space in Figure 1 would be called "online + traditional (legitimate) media usage", while the area in the top-left quarter (which is mostly empty in terms of the modalities' locations) would represent "offline + traditional (legitimate) media usage". Similarly, the area in the bottom-right quarter of the space would be called "online + traditional (legitimate) media non-usage", while the bottom-left quarter would represent the most passive media usage type - namely, "offline + traditional (legitimate) media non-usage". While arguably being a simplification of the space (which does not really include any 
categorical boundaries but instead gradual differences), such an image of four squares crystallises much of the two main dimensions of the space.

When considered this way, the top-right corner is the most privileged part (i.e., having the widest repertoire of media usage) and the bottom-left the most disadvantaged part of the space (i.e., having the narrowest repertoire of media usage). This interpretation is confirmed when the supplementary variables (and the sociopolitical divisions they manifest) are projected onto the space (see Figure 2). Indeed, university education, high income level, and liberal political attitudes all associate strongly with the top-right corner, while low education level, low income, and conservatism are found in the bottomleft corner. This diagonal opposition between the top-right and bottom-left areas of the space is the most crucial sociopolitical structuring principle of the Finnish media usage space in 2007. Thus, while the space of media usage itself is dominantly structured by axis 1 (online versus offline), the major sociopolitical division of the space combines both major axes, not only online but also traditional media-usage activities.

Figure 2 Sociodemographic variables and variables measuring party support and political attitudes (conservative versus liberal) in the Finnish space of media usage, 2007

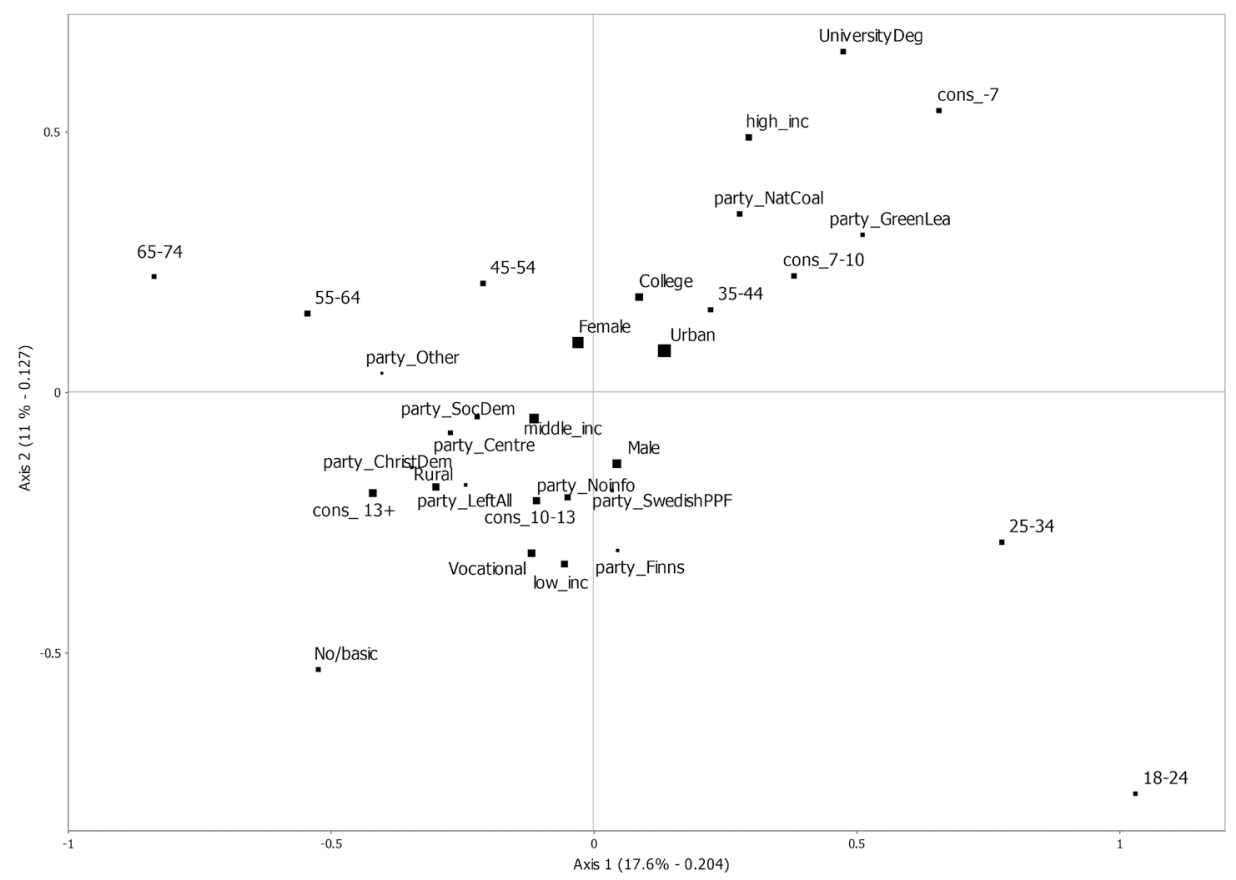

Comments: Shape size is proportional to their frequency in the sample.

Of the other sociodemographic factors superimposed onto the space, age makes a diagonal from the bottom-right area to the top-left. In other words, age mostly distinguishes between online (associated predominantly with younger groups) versus offline (older groups) media usage, but also between the axis of traditional media usage (older groups) and non-usage (younger groups). The difference between the location of genders is small. Similarly, residential area makes only a moderate difference, yet following the 
main opposition between the top-right (urban areas being associated with high volumes of capital and liberal attitudes) and bottom-left (rural areas being associated with low volumes of capital and conservative attitudes) of the space. Of the political variables, party support also makes a difference along the same, main diagonal, opposition: supporting the National Coalition Party or the Green League are located in the top-right area, while most of the other parties, such as the Left Alliance, Social Democratic Party, or Christian Democrats are located in the bottom-left quadrant, albeit relatively close to the midpoint. The populist Finns Party is located in the bottom-centre, next to vocational education and low income, thus being undifferentiated in terms of the online versus offline division, but leaning clearly towards the non-use of traditional legitimate media.

\section{Step 2: Assessing the effect of temporal change on the space of media usage}

For a detailed comparison of patterns of media usage in 2007 and 2018, we focused on 19 variables that are truly comparable across both years. With both datasets merged, step two of our approach focuses on studying individuals' graphical representation in the 2007 space of media usage (as constructed in the first step), with the addition of the 2018 individuals as supplementary.

Figure 3 Individuals in the space of media usage, 2007 and 2018
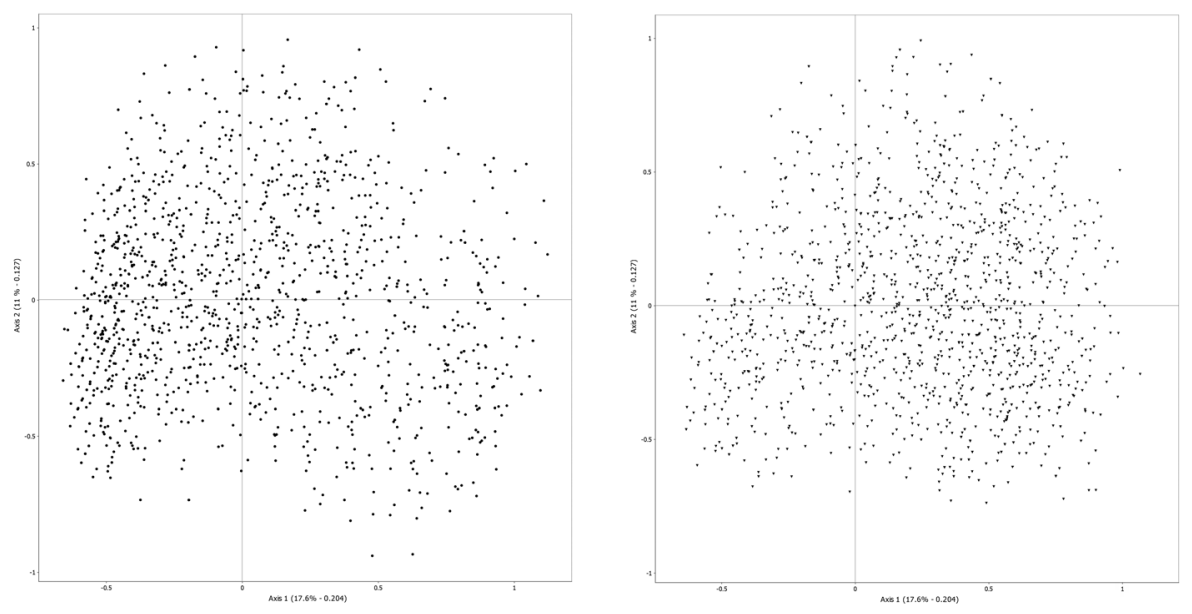

Comments: Left: 2007 individuals (active); right: 2018 individuals (supplementary).

Figure 3, with the 2007 individuals in the space of media usage in 2007 (left) and the 2018 individuals projected onto the same space (right), suggests a clear pattern of change. We can see that while the heaviest concentration of the 2007 individuals was in the vertical left side of the figure (the region characterised by lower Internet use and, in the case of the bottom-left quadrant, also non-use of traditional media), the 2018 individuals are scattered in the space much more evenly. In 2018, the vertical left side of the figure is relatively scarcely populated, and the concentration seems to have moved towards both right-hand quadrants (i.e., the region characterised by more Internet use). Changes in dispersion suggest that respondents have become less differentiated in terms 
of average media usage. This indicates a reduction in the number of individuals not using the Internet and of those individuals in the far-left categories on axis 1 (see Figure 1) having witnessed an increase in their media repertoires. This has led them to move towards the bottom-right quadrant, thus replacing Internet non-use with active usage, while remaining passive in terms of traditional (legitimate) media use.

Table 2 Individuals' mean and variance on axes 1 and 2, 2007 and 2018

\begin{tabular}{lccc}
\hline & $\mathbf{2 0 0 7}$ & $\mathbf{2 0 1 8}$ & Comparison (F-test) \\
\hline Axis 1 mean & .000 & .228 & $203.781(p=.000)^{\mathrm{a}}$ \\
Axis 1 variance & .204 & .157 & $35.897(p=.000)$ \\
Axis 2 mean & .000 & -.016 & $1.302(p=.254)^{\mathrm{b}}$ \\
Axis 2 variance & .127 & .124 & $.004(p=.949)$ \\
\hline
\end{tabular}

Comments: ${ }^{\mathrm{a}} \eta^{2}=0.068,{ }^{\mathrm{b}} \eta^{2}=0.001$.

Table 2 confirms the findings seen in Figure 3: average media usage has increased significantly while media use dispersion has decreased significantly. The increasing mean variation in axis 1 indicates that individuals are broadening their repertoires. However, statistically non-significant changes in the mean values for axis 2 suggest that changes are mostly due to higher Internet usage in 2018 (categories located on the far-right side of axis 1), rather than to changes in categories with a higher alignment with axis 2 (such as book or magazine readership). The eta-squared indicator confirms that a moderate amount of axis 1 total variance $(6.8 \%)$ can be accounted for by time change. There are no significant changes with regard to axis 2 . Taken together, the main change between 2007 and 2018 media usage spaces, using identical sets of indicators, is that the onlineoffline divide becomes less dominating due to the growing popularity of Internet. This is also reflected in the decrease of Benzécri's modified rate of axis 1 (from $77.1 \%$ in 2007 to $67.3 \%$ in 2018 ), and in the slight increase of the strength of axis 2 (from $19.2 \%$ to 23.6\%) when a separate MCA for 2018 sample using the 2007 indicators is performed (see Table A5 in the Supplementary Material file).

Step 3: Space of media usage in 2018 with additional indicators of online activities and social media

In the third step, we construct the space of media usage for the year 2018 by using, in addition to the same indicators as earlier, 16 additional indicators of social media and other online activities not covered in the 2007 questionnaire. This last step helps clarify the degree to which new, online-related activities have shaped the structure of media use and how they are related to eventual sociopolitical divisions. 
Table 3 Variances of axes, explained variances, and modified rates in constructing the space of media usage in Finland, 2018

\begin{tabular}{lccc}
\hline Axis & Variance & \% of explained variance & $\begin{array}{c}\text { Benzécri's modified } \\
\text { rates (\%) }\end{array}$ \\
\hline 1 & .163 & 14.6 & 79.0 \\
2 & .077 & 6.9 & 10.3 \\
3 & .062 & 5.6 & 5.0 \\
4 & .054 & 4.8 & 3.0 \\
5 & .048 & 4.3 & 1.8 \\
\hline
\end{tabular}

Comments: Using additional indicators of Internet and social media.

Again, as with Table 1 and the variances of the axes in 2007, the first two axes are distinct after the new indicators of social media and online activities are added (see Table 3). In terms of the Benzécri's modified rate, the first axis is stronger than in the 2007 analysis without the additional online indicators (while axis 2 is weaker). These differences are even more pronounced in comparison with the 2018 analysis, using identical indicators as in 2007 (see Table A5 in the Supplementary Material file), thus showing that including social media indicators in the analysis has revitalised the "newness" and divisive power of the online-offline divide in the space.

Figure 4 The space of media usage in Finland in 2018, axes 1 and 2

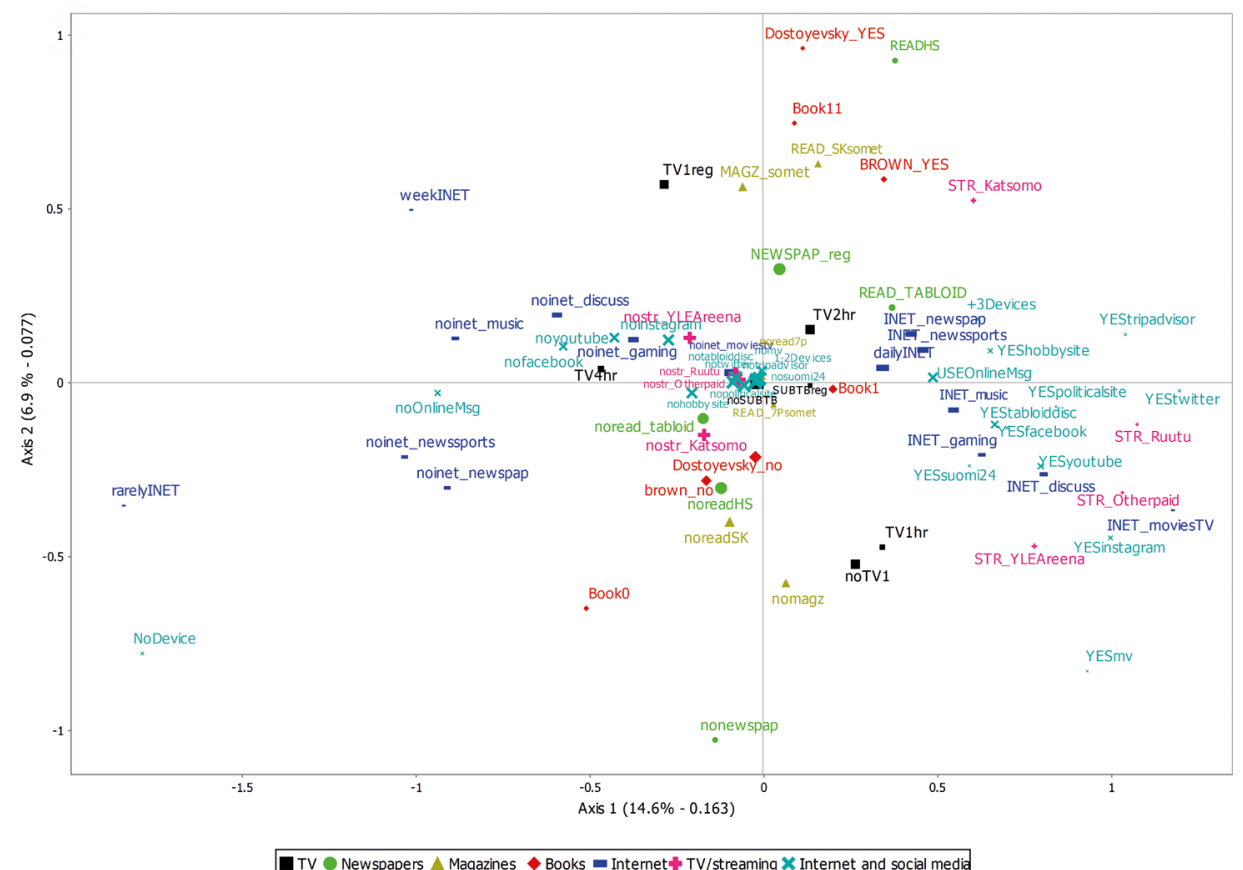

Comments: 74 modalities, including 33 new modalities of Internet and social media. Shape size is proportional to their frequency in the sample. 
The space itself is visualised in Figure 4 and detailed results are reported in the Supplementary Material file (see Tables A6 and A7). It is immediately apparent that the media usage space in 2018 is roughly similar to that of 2007. It is organised around the same dimensions - Internet use versus non-use and traditional media use versus non-use - as it was using the more limited set of indicators (see Figure 4). The first axis concerning Internet and social media activity is even more important for the space (see Table 3 for the Benzécri modified rate), but the actual change remains mostly in the organisation of the new online items, scattered in the right-hand quadrants. These are organised around specialised uses (top-right quadrant: Twitter, hobby sites, online newspapers) and entertainment-oriented uses (bottom-right quadrant: Instagram, gaming, YouTube) consistent with age. Furthest in the bottom-right quadrant is MV magazine, an online alternative media site accused of propagating hate speech and fake news.

The second dimension still represents traditional (legitimate) media usage (top quadrants) versus non-usage (lower quadrants). Interestingly, "never using Internet" has dropped vertically, showing that it is indeed associated with more general non-usage of traditional media. "No device" is located even further down, making it highly distinctive with regard to both axes. In general, while there is an increase in Internet usage (as reported in the previous step), the addition of further indicators of online behaviour makes Internet use an even more important distinction than before. This effectively shows the growing relevance of the Internet and social media as part of media repertoires. Apart from this important change, there are only few differences when using a more limited set of indicators. For instance, the locations of reading books and some newspapers remain very stable.

Projecting the supplementary variables measuring sociopolitical divisions into the space in Figure 5, it seems again that the overall picture is very similar as in 2007. The only remarkable difference seems to be the strong vertical differentiation of age, along with the traditional (legitimate) media usage axis. The two youngest age groups are strongly associated with non-usage of traditional media in 2018. The main lines of education, gender, and place of residence - as well as party support and conservative versus liberal political attitudes - remain roughly similar to 2007 (see Figure 5). 
Figure 5 Sociodemographic variables and variables measuring party support and political attitudes (conservative versus liberal) in the Finnish space of media usage, 2018

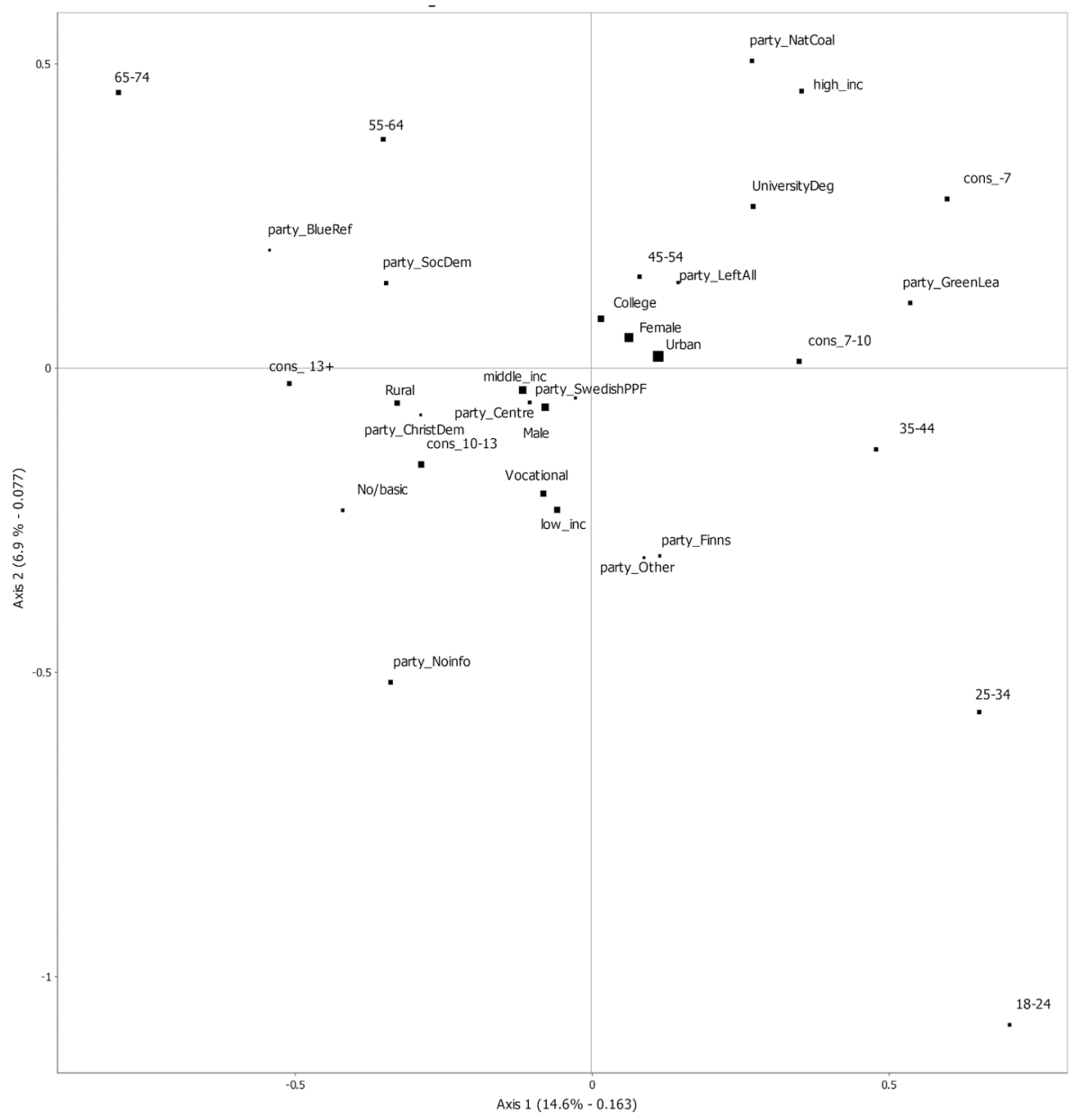

Comments: Shape size is proportional to their frequency in the sample.

\section{Conclusions}

In this article, we assessed the impact of the proliferation of online activities on the space of media usage in Finland using two nationally representative and comparative datasets on leisure and media practices, from 2007 and 2018. We focused on the association between media usage and sociopolitical divisions, asking whether these divisions have become steeper under the circumstances of a new, digitalised media landscape and increasingly polarised political culture. In this sense, our aim has been to answer the call of Beer (2013: 91), who lamented that "virtually no attention has been given to how cultural infrastructures and emergent media forms might be shaping, guiding and reshaping these apparently important cultural tastes and preferences". Beer pointed out that in our era of rapidly growing digitalisation, empirically investigating online-based activities as a relevant part of media repertoires is essential. 
Our main finding is that, in general, the structures of the spaces of media use were largely similar and were organised around the same main axes of Internet use versus non-use and traditional (legitimate) media use versus non-use. This was true both in 2007 and 2018, without remarkable changes in their sociodemographic, class-related, or political structuring. The stability is largely due to the fact that already in 2007 , the online-offline divide was the most powerful dimension structuring the space of media usage in Finland. However, we also found a notable increase in Internet usage and a general broadening of repertoires. When measured with similar indicators as in 2007 , the online-offline divide in 2018 had lost part of its divisive power, but when measured with a more comprehensive set of new online indicators, the online-offline divide in 2018 was stronger than in 2007.

Overall, our results point to continuity in the media ecology (cf. Scolari, 2012): online activities have not appeared to explode existing media practices. Rather, they seem to settle upon already existing divisions and hierarchies organised mostly along traditional socioeconomic inequalities and age. We saw that serious or specialist and entertainment-oriented Internet use go hand-in-hand with differences in the use of traditional media, with serious Internet use being linked to traditional (legitimate) media and entertainment-oriented Internet use to withdrawal from traditional media use. This leads to another important finding: in 2018, non-users of both traditional media and the Internet seem to fall further behind other groups (see also Heikkilä et al., 2020). These insights are crucial to gaining a better understanding of the logics of the new digitally oriented media ecology as an integral part of media practices and repertoires.

With regard to the debates on the digital divide literature (e.g., Scheerder et al., 2017; Zillien \& Hargittai, 2009) and scholars emphasising that new media reproduces similar patterns of stratification as elsewhere (e.g., Lindell \& Hovden, 2018; Mihelj et al., 2019; Ørmen, 2019) on the one hand, and the debates on digital platforms and social media as potentially transformational for status distinctions (e.g., Beer, 2013; Webster, 2019, 2020) on the other, our results can be interpreted primarily as stressing the importance of stability. We found that the structure of the space of media use was largely similar in 2007 and 2018, while simultaneously, we witnessed a broadening of media repertoires and new influences. However, the digital divide, proceeding not only along socioeconomic and age-related lines (e.g., Zillien \& Hargittai, 2009), but also along political orientations (especially the division between conservative and liberal attitudes; cf. DellaPosta et al., 2015), seems to be relevant even for a context such as Finland, one of the world's top technological countries. While Internet use becomes more common, it differentiates more strongly than ever between users and non-users, making non-users, who simultaneously fall away from the reach of traditional media, dropouts within a media welfare state (cf. Heikkilä et al., 2020).

As always, some limitations should be kept in mind. Our research context is Finland, a relatively resource-rich Nordic society with a large share of publicly broadcasted media and wide access to technological devices and the Internet. In a way, this fact could actually accentuate our findings: wide media repertoires could be available to everyone, for instance, through relatively inexpensive Internet connections and public services such as the public library network. Thus, it could be expected that in countries with more pronounced class inequalities than Finland, similar patterns of sociopolitical stratification of media usage would be even stronger. Finally, survey methodology and 
the population-level perspective create their own limitations, even if the samples are nationally representative and the repeated data collection procedures capable of tracking changes over time. The approach undertaken in this study has not been able to discern the motivations, reasons, or perceived symbolic boundaries of specific media choices or practices. Thus, it remains an open question whether and how online activities might have changed the games of status distinctions, even if the macro-level structures of media usage stratification have mostly stayed intact. This makes a qualitative analysis of changing media usage a logical and necessary next step.

\section{Funding}

The research was made possible by the funding from the Academy of Finland (grant no. 309181) and the support received from the Institute of Advanced Studies at Loughborough University.

\section{References}

Beer, D. (2013). Popular culture and new media: The politics of circulation. Basingstoke: Palgrave Macmillan. https://doi.org/10.1057/9781137270061

Bergström, A., Strömbäck, J., \& Arkhede, S. (2019). Towards rising inequalities in newspaper and television news consumption? A longitudinal analysis, 2000-2016. European Journal of Communication, 34(2), 175-189. https://doi.org/10.1177/0267323119830048

Boulianne, S. (2011). Stimulating or reinforcing political interest: Using panel data to examine reciprocal effects between news media and political interest. Political Communication, 28(2), 147-162. https:// doi.org/10.1080/10584609.2010.540305

Bourdieu, P. (1984). Distinction: A social critique of the judgement of taste. London: Routledge.

Coulangeon, P. (2013). Changing policies, challenging theories and persisting inequalities: Social disparities in cultural participation in France from 1981 to 2008. Poetics, 41(2), 177-209. https://doi.org/10.1016/j. poetic.2012.12.003

Couldry, N., Livingstone, S., \& Markham, T. (2010). Media consumption and public engagement. Houndmills: Palgrave. https://doi.org/10.1057/9780230800823

DellaPosta, D., Shi, Y., \& Macy, M. (2015). Why do liberals drink lattes? American Journal of Sociology, 120(5), 1473-1511. https://doi.org/10.1086/681254

DiMaggio, P., Evans, J., \& Bryson, B. (1996). Have American's social attitudes become more polarized? American Journal of Sociology, 102(3), 690-755. https://doi.org/10.1086/230995

DiMaggio, P., Hargittai, E., Celeste, C., \& Shafer, S. (2004). Digital inequality: From unequal access to differentiated use. In K. M. Neckerman (Ed.), Social inequality (pp. 355-400). New York: Russell Sage Foundation.

Dubois, E., \& Blank, G. (2018). The echo chamber is overstated: The moderating effect of political interest and diverse media. Information, Communication \& Society, 21(5), 729-745. https://doi.org/10.1080/1 369118X.2018.1428656

Friedman, S., Savage, M., Hanquinet, L., \& Miles, A. (2015). Cultural sociology and new forms of distinction. Poetics, 53, 1-8. https://doi.org/10.1016/j.poetic.2015.10.002

Greenacre, M. (2007). Correspondence analysis in practice. Boca Raton, Florida: CRC Press.

Hallin, D. C., \& Mancini, P. (2004). Comparing media systems: Three models of media and politics. Cambridge: Cambridge University Press. https://doi.org/10.1017/CBO9780511790867

Harrits, G. S., Prieur, A., Rosenlund, L., \& Skjott-Larsen, J. (2010). Class and politics in Denmark: Are both old and new politics structured by class? Scandinavian Political Studies, 33(1), 1-27. https://doi. org/10.1111/j.1467-9477.2008.00232.x

Hasebrink, U., \& Popp, J. (2006). Media repertoires as a result of selective media use: A conceptual approach to the analysis of patterns of exposure. Communications, 31(3), 369-387. https://doi.org/10.1515/ COMMUN.2006.023

Heikkilä, R., Leguina, A., \& Purhonen, S. (2020, November 5). The stratification of media usage in Finland, 2007-2018: Signs of socio-political polarization? New Media \& Society. Advance online publication. https://doi.org/10.1177/1461444820971612

Hjellbrekke, J. (2019). Multiple correspondence analysis for the social sciences. London: Routledge. https:// doi.org/10.4324/9781315516257 
Jarness, V., Flemmen, M. P., \& Rosenlund, L. (2019). From class politics to classed politics. Sociology, 53(5), 879-899. https://doi.org/10.1177/0038038519838740

Koiranen, I., Keipi, T., Koivula, A., \& Räsänen, P. (2020). Changing patterns of social media use? A population-level study of Finland. Universal Access in the Information Society, 19, 603-617. https://doi. org/10.1007/s10209-019-00654-1

Kristensen, N. N., Haastrup, H. K., \& Holdgaard, N. (2018). Cultural critique: Re-negotiating cultural authority in the digital media culture. MedieKultur, 34(65), 3-9. https://doi.org/10.7146/mediekultur. v34i65.111265

Le Roux, B., \& Rouanet, H. (2004). Geometric data analysis: From correspondence analysis to structured data analysis. Dordrecht, Netherlands: Kluwer. https://doi.org/10.1007/1-4020-2236-0

Le Roux, B., \& Rouanet, H. (2010). Multiple correspondence analysis. Thousand Oaks, California: Sage. https://doi.org/10.4135/9781412993906

Lindell, J. (2018). Distinction recapped: Digital news repertoires in the class structure. New Media \& Society, 20(8), 3029-3049. https://doi.org/10.1177/1461444817739622

Lindell, J., \& Hovden, J. F. (2018). Distinctions in the media welfare state: Audience fragmentation in post-egalitarian Sweden. Media, Culture \& Society, 40(5), 639-655. https://doi.org/10.1177/0163443717746230

Mihelj, S., Leguina, A., \& Downey, J. (2019). Culture is digital: Cultural participation, diversity and the digital divide. New Media \& Society, 21(7), 1465-1485. https://doi.org/10.1177/1461444818822816

Müller-Schneider, T. (1994). The visualization of structural change by means of correspondence analysis. In M. Greenacre, \& J. Blasius (Eds.) Correspondence analysis in the social sciences (pp. 267-280). London: Academic Press.

Norris, P. (2001). Digital divide: Civic engagement, information poverty, and the Internet worldwide. Cambridge: Cambridge University Press. https://doi.org/10.1017/CBO9781139164887

Prieur, A., \& Savage, M. (2013). Emerging forms of cultural capital. European Societies, 15(2), 246-267. https://doi.org/10.1080/14616696.2012.748930

Prior, M. (2007). Post-broadcast democracy: How media choice increases inequality in political involvement and polarizes elections. Cambridge: Cambridge University Press. https://doi.org/10.1017/ CBO9781139878425

Purhonen, S. (2020). El espacio de los estilos de vida en una sociedad igualitaria: el caso de Finlandia [The space of lifestyles in an egalitarian society: The case of Finland]. In L. E. Alonso, C. J. Fernández Rodríguez, \& R. Ibáñez Rojo (Eds.), Estudios sociales sobre el consumo [Social studies on consumption] (pp. 425-448). Madrid: CIS.

Purhonen, S., Gronow, J., Heikkilä, R., Kahma, N., Rahkonen, K., \& Toikka, A. (2014). Suomalainen maku: Kulttuuripääoma, kulutus ja elämäntyylien sosiaalinen eriytyminen [The Finnish taste: Cultural capital, consumption and the social stratification of lifestyles]. Helsinki: Gaudeamus Helsinki University Press.

Purhonen, S., Heikkilä, R., Karademir Hazir, I., Lauronen, T., Fernández Rodríguez, C. J., \& Gronow, J. (2019). Enter culture, exit arts? The transformation of cultural hierarchies in European newspaper culture sections, 1960-2010. London: Routledge. https://doi.org/10.4324/9781315183404

Rosenlund, L. (2019). The persistence of inequalities in an era of rapid social change: Comparisons in time of social spaces in Norway. Poetics, 74, Article 101323. https://doi.org/10.1016/j.poetic.2018.09.004

Savage, M. (2015). Social class in the 21st century. London: Pelican.

Savage, M., Devine, F., Cunningham, N., Taylor, M., Li, Y., Hjellbrekke, J., Le Roux, B., Friedman, S., \& Miles, A. (2013). A new model of social class? Findings from the BBC's Great British Class Survey experiment. Sociology, 47(2), 219-250. https://doi.org/10.1177/0038038513481128

Scheerder, A. J., van Deursen, A. J. A. M., \& van Dijk, J. A. G. M. (2017). Determinants of Internet skills, uses and outcomes: A systematic review of the second-and third-level digital divide. Telematics and Informatics, 34(8), 1607-1624. https://doi.org/10.1016/j.tele.2017.07.007

Scolari, C. A. (2012). Media ecology: Exploring the metaphor to expand the theory. Communication Theory, 22(2), 204-225. https://doi.org/10.1111/j.1468-2885.2012.01404.x

Strömbäck, J., Djerf-Pierre, M., \& Shehata, A. (2013). The dynamics of political interest and news media consumption: A longitudinal perspective. International Journal of Public Opinion Research, 25(4), 414-435. https://doi.org/10.1093/ijpor/eds018

Syvertsen, T., Enli, G., Mjøs, O. J., \& Moe, H. (2014). The media welfare state: Nordic media in the digital era. Ann Arbor, Michigan: University of Michigan Press. https://doi.org/10.3998/nmw.12367206.0001.001

Tucker, J. A., Guess, A., Barbera, P., Vaccari, C., Siegel, A., Sanovich, S., Stukal, D., \& Nyhan, B. (2018). Social media, political polarization, and political disinformation: A review of the scientific literature. SSRN report. https://doi.org/10.2139/ssrn.3144139

Verboord, M. (2014). The impact of peer-produced criticism on cultural evaluation: A multilevel analysis of discourse employment in online and offline film reviews. New Media \& Society, 16(6), 921-940. https:// doi.org/10.1177/1461444813495164 
Webster, J. (2019, November 22). Music on-demand: A commentary on the changing relationship between music taste, consumption and class in the streaming age. Big Data \& Society. Advance online publication. https://doi.org/10.1177/2053951719888770

Webster, J. (2020). Taste in the platform age: Music streaming services and new forms of class distinction. Information, Communication \& Society, 23(13), 1909-1924. https://doi.org/10.1080/136911 8X.2019.1622763

Weingartner, S., \& Rössel, J. (2019). Changing dimensions of cultural consumption? The space of lifestyles in Switzerland from 1976 to 2013. Poetics, 74, Article 101345. https://doi.org/10.1016/j.poetic.2019.01.001

Wright, D. (2015). Understanding cultural taste: Sensation, skill and sensibility. Basingstoke: Palgrave Macmillan. https://doi.org/10.1057/9781137447074

Xenos, M., Vromen, A., \& Loader, B.D. (2014). The great equalizer? Patterns of social media use and youth political engagement in three advanced democracies. Information, Communication \& Society, 17(2), 151-167. https://doi.org/10.1080/1369118X.2013.871318

Yuen, A. H. K., Park, J., Chen, L., \& Cheng, M. (2018). The significance of cultural capital and parental mediation for digital inequity. New Media \& Society, 20(2), 599-617. https://doi.org/10.1177/1461444816667084

Zillien, N., \& Hargittai, E. (2009). Digital distinction: Status-specific types of Internet usage. Social Science Quarterly, 90(2), 274-291. https://doi.org/10.1111/j.1540-6237.2009.00617.x

Ørmen, J. (2019). Not so distinct after all: Assessing social stratification of news users on the web. Journalism Studies, 20(11), 1653-1670. https://doi.org/10.1080/1461670X.2018.1539342

(C) 2021 Nordicom and respective authors. This is an Open Access work licensed under the terms of the Creative Commons Attribution-NonCommercial-NoDerivatives 4.0 International Public licence (CC BY-NC-ND 4.0). To view a copy of the licence, visit https://creativecommons.org/ licenses/by-nc-nd/4.0/ 